\title{
Editorial: Understanding and Engineering Antibody-Superantigen Interactions
}

\author{
Samuel Ken-En Gan ${ }^{1,2,3 *}$, Jeremy P. Derrick ${ }^{4 *}$ and Franca Fraternali ${ }^{5,6,7 *}$ \\ ${ }^{1}$ Antibody \& Product Development (APD) Lab, Agency for Science, Technology, and Research (A*STAR), Singapore, Singapore, \\ ${ }^{2}$ APD SKEG Pte Ltd, Singapore, Singapore, ${ }^{3}$ James Cook University, Singapore, Singapore, ${ }^{4}$ School of Biological Sciences, \\ Faculty of Biology, Medicine, and Health, University of Manchester, Manchester, United Kingdom, ${ }^{5}$ Randall Division of Cell and \\ Molecular Biophysics, King's College London, London, United Kingdom, 6 The Francis Crick Institute, London, United Kingdom, \\ 7 The Thomas Young Centre for Theory and Simulation of Materials, London, United Kingdom
}

Keywords: superantigens, antibody engineering, protein-protein interactions, antibodies, protein A, protein G, protein L

Editorial on the Research Topic

Understanding and Engineering Antibody-Superantigen Interactions

Superantigens are classically defined as antigens that induce hyperactivation of the immune system. They are traditionally associated with non-specific activation of T-cells that induces abnormal cytokine release. A search for the term 'superantigens' on Google in January 2022 yielded results with a heavy bias towards T-cell superantigens (1-4) which were first described in 1989 (5). Almost 30 years later, the T-cell centric view of superantigens continues to overshadow B-cell or antibody superantigens, even though reports of B-cell superantigens date back at least to 1966 for Protein A (6) and 1984 for Protein G (7). Implementation for antibody purification followed rapidly, assisting the development of therapeutic antibodies. In the early 1990s, applications of superantigens expanded towards potential therapeutics, particularly against cancer (8-11). These earlier studies are now bearing fruition: for example, a recent review of the literature on the application of Staphylococcal enterotoxins in cancer immunotherapy found over 50 studies, of which Staphylococcal enterotoxin A was the most common superantigen employed (12). Fusions of superantigens with, for example, antibody Fab fragments which are targeted against tumourassociated antigens have been shown to be effective against melanoma and other cancers (12). Superantigens have also found recent application in CAR-T therapy; von Scheidt et al. demonstrated that inhibition of solid tumour growth in mice was potentiated by pre-incubation of CAR T cells with Staphylococcal enterotoxin B (13). Although most of these studies to date have used mouse models, translation of some applications to the clinic in the near future seems likely.

Intensive research into SARS-CoV-2, driven by the current pandemic, has identified an interesting link between toxic shock syndrome, bacterial superantigens and the viral $\mathrm{S}$, or spike, protein that is the basis for many vaccination strategies against the virus. A sequence motif within the $\mathrm{S}$ protein resembles a section within Staphylococcal enterotoxin B. Cheng et al. showed how this can be exploited through development of a monoclonal antibody against the site, which is able to block viral entry into cells (14). This work represents a novel strategy for exploiting a superantigen structure for therapeutic applications. 
Given these widespread applications in antibody labelling, purification and immunotherapy, it is apposite to consider what unifying features there may be which apply to the large and diverse superantigen family. A review in this Research Topic uses a broad definition of the term 'superantigen' to include antibodydirected, as well as T-cell-directed molecules (Deacy et al.). A number of similarities are identified in the recognition properties between immune macromolecule (e.g. antibody, MHC) and cognate superantigen. Compared with all protein-protein complexes within the Protein Data Bank, such complexes fall within a relatively small range when considering the physical characteristics of each interface. Interestingly, B-cell and T-cell directed superantigens do not obviously segregate (see Figure 9 in Deacy et al.). This observation suggests a degree of structural, as well as functional, congruence which argues for a broader definition of the term 'superantigen'.

Extending the term superantigen further is likely to prove controversial but we propose that other, probably more remote, additions to the family are likely to be advocated in the future. In this Research Topic, we have one such provocative article (Su et al.) demonstrating superantigen-like binding of nickel to antibodies. Although nickel does not fit the typical definitions of antigen or superantigen, it is a known aggravator of metal allergies. Some investigators have sought to exclude nickel as a formal T-cell superantigen based on the recognition properties (15) alone, despite there being functional similarities by nickel to known superantigens (16).

With recent suggestions that unnecessary immune system exposure to the environment may underlie many disease pathogenesis in the 'epithelial barrier hypothesis' (17), there is certainly much to investigate on the roles of superantigens in pathogenesis. It is interesting that, together with superantigens, the 'epithelial barrier hypothesis' has intersections with the 'hygiene hypothesis', first proposed in 1989 (18); discussions on the intersection are ongoing (19-21). In addition to potential

\section{REFERENCES}

1. Proft T, Fraser JD. Bacterial Superantigens. Clin Exp Immunol (2003) 133 (3):299-306. doi: 10.1046/j.1365-2249.2003.02203.x

2. Rich RR. 1 - The Human Immune Response. In: RR Rich, TA Fleisher, WT Shearer, HW Schroeder, AJ Frew, CM Weyand, editors. Clinical Immunology, 4th ed. London: Elsevier (2013). p. 3-15.

3. Kotzin BL, Leung DY, Kappler J, Marrack P. Superantigens and Their Potential Role in Human Disease. Adv Immunol (1993) 54:99-166. doi: 10.1016/s0065-2776(08)60534-9

4. Saline M, Rödström KEJ, Fischer G, Orekhov VY, Karlsson BG, LindkvistPetersson K. The Structure of Superantigen Complexed With TCR and MHC Reveals Novel Insights Into Superantigenic T Cell Activation. Nat Commun (2010) 1(1):119. doi: 10.1038/ncomms1117

5. Marrack P, Kappler J. The Staphylococcal Enterotoxins and Their Relatives. Science (1990) 248(4956):705-11. doi: 10.1126/science.2185544

6. Forsgren A, Sjöquist J. "Protein a" From S. Aureus. I Pseudo-Immune Reaction With Human $\gamma$-Globulin. J Immunol (1966) 97(6):822-7.

7. Björck L, Kronvall G. Purification and Some Properties of Streptococcal Protein G, A Novel IgG-Binding Reagent. J Immunol (1984) 133(2):969-74.

8. Dohlsten M, Hedlund G, Akerblom E, Lando PA, Kalland T. Monoclonal Antibody-Targeted Superantigens: A Different Class of Anti-Tumor Agents. Proc Natl Acad Sci USA (1991) 88(20):9287-91. doi: 10.1073/ pnas.88.20.9287 roles in disease pathogenesis implied by both the 'hygiene' and 'epithelial barrier' hypotheses, superantigen-antibody interactions also underpin the behavior of the natural gut flora by maintaining healthy IgA levels (22). Such interactions may explain the bias in VH genes that mediate Staphylococcal Protein A interaction in humans by Radke et al. Other recent studies have extended such considerations to $\operatorname{IgE}(23)$ and, as mentioned above, with respect to nickel binding (Su et al.).

Given the possible confounding interactions from the local microflora on therapeutics in pharmacomicrobiomics, further investigation into superantigen recognition and its biological implications is well justified. A holistic (24) approach, previously used to study the impact of antibody regions (25-30) distally on each other as allosteric, was also used in the Research Topic to find additional target sites in Staphylococcal enterotoxin B (SEB) with therapeutic potential (Bai et al.).

We are presenting in this Research Topic findings that encourage a revision of more restrictive definitions of the term 'superantigen' and their applications in biomedicine. We hope this will stimulate novel research approaches that further stimulate a re-examination of the biological functions and applications in therapeutics, diagnostics, and biotechnology of superantigens.

\section{AUTHOR CONTRIBUTIONS}

All authors contributed to the article and approved the submitted version.

\section{ACKNOWLEDGMENTS}

We thank the publisher, the contributing authors, the reviewers and associated editors in their effort to make this Research Topic possible to our readers.

9. Abrahmsén L. Superantigen Engineering. Curr Opin Struct Biol (1995) 5 (4):464-70. doi: 10.1016/0959-440X(95)80030-1

10. Alpaugh RK, Schultz J, McAleer C, Giantonio BJ, Persson R, Burnite M, et al. Superantigen-Targeted Therapy: Phase I Escalating Repeat Dose Trial of the Fusion Protein PNU-214565 in Patients With Advanced Gastrointestinal Malignancies. Clin Cancer Res (1998) 4(8):1903-14.

11. Hansson J, Ohlsson L, Persson R, Andersson G, Ilback NG, Litton MJ, et al. Genetically Engineered Superantigens as Tolerable Antitumor Agents. Proc Natl Acad Sci USA (1997) 94(6):2489-94. doi: 10.1073/pnas.94.6.2489

12. Shivaee A, Sedighi M, Imani Fooladi AA. Staphylococcal Enterotoxins as Good Candidates for Cancer Immunotherapy: A Systematic Review. Ann Ig (2020) 32(6):648-63. doi: 10.7416/ai.2019.2386

13. von Scheidt B, Wang M, Oliver AJ, Chan JD, Jana MK, Ali AI, et al. Enterotoxins can Support CAR T Cells Against Solid Tumors. Proc Natl Acad Sci (2019) 116(50):25229-35. doi: 10.1073/pnas.1904618116

14. Cheng MH, Porritt RA, Rivas MN, Krieger JM, Ozdemir AB, Garcia G Jr, et al. A Monoclonal Antibody Against Staphylococcal Enterotoxin B Superantigen Inhibits SARS-CoV-2 Entry In Vitro. Structure (2021) 29(9):951-62.e3. doi: 10.1016/j.str.2021.04.005

15. Vollmer J, Weltzien HU, Moulon C. TCR Reactivity in Human Nickel Allergy Indicates Contacts With Complementarity-Determining Region 3 But Excludes Superantigen-Like Recognition. J Immunol (1999) 163(5):2723-31.

16. Yin L, Crawford F, Marrack P, Kappler JW, Dai S. T-Cell Receptor (TCR) Interaction With Peptides That Mimic Nickel Offers Insight Into Nickel 
Contact Allergy. Proc Natl Acad Sci USA (2012) 109(45):18517-22. doi: 10.1073/pnas.1215928109

17. Akdis CA. Does the Epithelial Barrier Hypothesis Explain the Increase in Allergy, Autoimmunity and Other Chronic Conditions? Nat Rev Immunol (2021) 21(11):739-51. doi: 10.1038/s41577-021-00538-7

18. Strachan DP. Hay Fever, Hygiene, and Household Size. BMJ (1989) 299 (6710):1259-60. doi: 10.1136/bmj.299.6710.1259

19. Shoja MM, Tubbs RS, Ghaffari A, Loukas M, Agutter PS. Rethinking the Origin of Chronic Diseases. BioScience (2012) 62(5):470-8. doi: 10.1525/ bio.2012.62.5.8

20. Seiberling KA, Grammer LC, Kern RC. Chronic Rhinosinusitis and Superantigens. In: FJ Stucker, C de Souza, GS Kenyon, TS Lian, W Draf, B Schick, editors. Rhinology and Facial Plastic Surgery. Berlin, Heidelberg: Springer Berlin Heidelberg (2009). p. 231-9.

21. Renz H, Herz U. The Bidirectional Capacity of Bacterial Antigens to Modulate Allergy and Asthma. Eur Respir J (2002) 19(1):158-71. doi: 10.1183/ 09031936.02.00254202

22. Bunker JJ, Drees C, Watson AR, Plunkett CH, Nagler CR, Schneewind O, et al. B Cell Superantigens in the Human Intestinal Microbiota. Sci Transl Med (2019) 11(507):1226-42. doi: 10.1126/scitranslmed.aau9356

23. Lua WH, Su CT, Yeo JY, Poh JJ, Ling WL, Phua SX, et al. Role of the IgE Variable Heavy Chain in FcepsilonRIalpha and Superantigen Binding in Allergy and Immunotherapy. J Allergy Clin Immunol (2019) 144(2):51423.e5. doi: 10.1016/j.jaci.2019.03.028

24. Phua SX, Chan KF, Su CTT, Poh JJ, Gan SKE. Perspective: The Promises of a Holistic View of Proteins - Impact on Antibody Engineering and Drug Discovery. Biosci Rep (2019) 39(1):BSR20181958. doi: 10.1042/BSR20181958

25. Su CTT, Lua WH, Ling WL, Gan SKE. Allosteric Effects Between the Antibody Constant and Variable Regions: A Study of IgA Fc Mutations on Antigen Binding. Antibodies (2018) 7(2):20. doi: 10.3390/antib7020020

26. Lua WH, Ling WL, Yeo JY, Poh JJ, Lane DP, Gan SKE. The Effects of Antibody Engineering $\mathrm{CH}$ and $\mathrm{CL}$ in Trastuzumab and Pertuzumab Recombinant Models: Impact on Antibody Production and AntigenBinding. Sci Rep (2018) 8(1):718. doi: 10.1038/s41598-017-18892-9
27. Zhao J, Nussinov R, Ma B. Antigen Binding Allosterically Promotes Fc Receptor Recognition. MAbs (2019) 11(1):58-74. doi: 10.1080/19420862.2018.1522178

28. Lua WH, Su CTT, Yeo JY, Poh JJ, Ling WL, Phua SX, et al. Role of the IgE Variable Heavy Chain in Fcerio and Superantigen Binding in Allergy and Immunotherapy. J Allergy Clin Immunol (2019) 144(2):514-23.e5. doi: 10.1016/j.jaci.2019.03.028

29. Ling WL, Lua WH, Poh JJ, Yeo JY, Lane DP, Gan SKE. Effect of VH-VL Families in Pertuzumab and Trastuzumab Recombinant Production, Her2 and Fcyiia Binding. Front Immunol (2018) 9:469. doi: 10.3389/fimmu.2018.00469

30. Su CTT, Ling WL, Lua WH, Poh JJ, Gan SKE. The Role of Antibody Vк Framework 3 Region Towards Antigen Binding: Effects on Recombinant Production and Protein L Binding. Sci Rep (2017) 7:3766. doi: 10.1038/ s41598-017-02756-3

Conflict of Interest: Author SG was employed by company APD SKEG Pte Ltd.

The remaining authors declare that the research was conducted in the absence of any commercial or financial relationships that could be construed as a potential conflict of interest.

Publisher's Note: All claims expressed in this article are solely those of the authors and do not necessarily represent those of their affiliated organizations, or those of the publisher, the editors and the reviewers. Any product that may be evaluated in this article, or claim that may be made by its manufacturer, is not guaranteed or endorsed by the publisher.

Copyright $\odot 2022$ Gan, Derrick and Fraternali. This is an open-access article distributed under the terms of the Creative Commons Attribution License (CC BY). The use, distribution or reproduction in other forums is permitted, provided the original author(s) and the copyright owner(s) are credited and that the original publication in this journal is cited, in accordance with accepted academic practice. No use, distribution or reproduction is permitted which does not comply with these terms. 